\title{
COMMENTARY
}

\section{Lung recruitment in ARDS: We are still confused, but on a higher PEEP level}

\author{
Peter M Spieth and Marcelo Gama de Abreu* \\ See related research by de Matos et al., http://ccforum.com/content/16/1/R4
}

\begin{abstract}
Recruitment maneuvers and the application of high levels of positive end-expiratory pressure combined with lung protective mechanical ventilation strategies have been proposed to improve pulmonary function in patients with severe acute respiratory distress syndrome. However, the optimal way to achieve and maintain alveolar recruitment is still under debate.
\end{abstract}

In this issue of Critical Care, de Matos and colleagues [1] report a case series of 51 patients with early severe acute respiratory distress syndrome (ARDS) treated with the so-called maximum recruitment strategy (MRS). The authors found sustained improved oxygenation and reduction of collapsed lung tissue, which were suggestive of high degrees of alveolar recruitability.

The concept of alveolar recruitment and maintenance of high levels of positive end-expiratory pressure (PEEP) was proposed 20 years ago [2]. However, experimental as well as clinical results are still controversial and the why, how, and when of recruitment and PEEP settings are still under debate. Recent studies have questioned the concept of lung recruitability in severe ARDS in general and reported high variability of potentially recruitable lung tissue as well as an association with patient response to PEEP [3]. Although three prospective randomized clinical trials could not show decreased mortality with lung protective mechanical ventilation aiming at alveolar recruitment and the application of higher PEEP levels, better oxygenation and improvement in a relevant secondary endpoint (namely less need for rescue therapies) have been achieved [4-6]. Furthermore, a recent metaanalysis [7] suggested a survival benefit for protective

${ }^{*}$ Correspondence: mgabreu@uniklinikum-dresden.de

Pulmonary Engineering Group, Department of Anesthesiology and Intensive Care Therapy, University Hospital Carl Gustav Carus, Dresden University of Technology, Fetschertsrasse 74, 01307 Dresden, Germany mechanical ventilation at higher levels of PEEP in patients with severe ARDS. On the other hand, according to the same analysis [7], patients with less severe ARDS did not show improved survival and even needed more time to be extubated. Thus, it is crucial to define the right patient population (severe versus mild ARDS), the right time (early versus late ARDS), and the right method to achieve and maintain alveolar recruitment without causing structural damage to the lungs or compromising hemodynamics.

There are numerous ways to achieve alveolar recruitment, and so far there is no gold standard to set PEEP, to recruit previously atelectatic lung regions in a standardized fashion, or even to define adequate alveolar recruitment. Sustained inflation (that is, a continuous level of high pressure applied to the airways) is the most popular recruitment maneuver. However, it has a major impact on hemodynamics and has been shown to worsen lung damage and inflammation in experimental acute lung injury in comparison with smoother maneuvers [8]. Also, sustained inflation has been applied with different airway pressures and durations but without objective endpoints. Compared with other methods, the MRS is a well-protocolized alternative targeted at well-defined endpoints. It consists of an initial recruitment phase with stepwise increase of PEEP (beginning, for example, at $20 \mathrm{~cm} \mathrm{H}_{2} \mathrm{O}$ ) and a fixed inspiratory driving pressure (for example, $15 \mathrm{~cm} \mathrm{H}_{2} \mathrm{O}$ ) until either the lungs are fully recruited, as measured by gas exchange or computed tomography, or peak airway pressures reach $60 \mathrm{~cm} \mathrm{H}_{2} \mathrm{O}$ (at a PEEP of $45 \mathrm{~cm} \mathrm{H}_{2} \mathrm{O}$ ). The recruitment phase is followed by a decremental PEEP trial aiming at defining the optimal PEEP (that is, one step above the PEEP level at which closing of lung areas could be obtained), which is an important part of the concept. The MRS has been used in patients, yielding significant and long-lasting improvement of lung function [1,9]. However, it has been criticized, mainly because of the potential for deterioration of hemodynamics at increased levels of PEEP.

The timely study by de Matos and colleagues [1] is intriguing for two reasons. First, inspiratory plateau 
pressures in their patient population far exceeded the $28 \mathrm{~cm} \mathrm{H}_{2} \mathrm{O}$ safety limit, which had been associated with increased inflammatory response in a previous study [10], and even the $30 \mathrm{~cm} \mathrm{H}_{2} \mathrm{O}$ cutoff proposed by the ARDS Network. In fact, it is almost certain that the inspiratory plateau pressure of approximately $40 \mathrm{~cm} \mathrm{H}_{2} \mathrm{O}$ (on average!) measured after MRS resulted in high degrees of stress/strain in those patients [1]. However, given the severity of disease, mortality rates were not higher than expected, and no significant pulmonary or extrapulmonary complications were reported. Second, the potential for recruitability was much higher than the average of approximately 13\%, as reported in a randomized clinical trial [3]. The immediate question that arises is how to explain those discrepancies.

Strain is a relative measurement that takes into account the initial length/volume of a material with elastic properties. In the case of the lungs, the initial volume should, ideally, be measured at the barometric pressure. The product of strain and intrinsic elastance yields stress, which can be translated as transpulmonary pressure. However, such calculations assume a homogeneous distribution of volume. It has been known since 1970 that neighbor lung zones with non-homogeneous elastic properties undergo higher stress [11]. Thus, the MRS may contribute to homogenize the stress distribution across the lungs, decreasing local stress. In other words, less (inspiratory plateau pressure) can be also more (local stress/strain) in a non-homogeneous lung. Or is the dynamic stress/strain, which is closer to the driving pressure, what counts more? The higher degree of lung recruitability in the study by de Matos and colleagues [1] could be ascribed to a highly efficient recruitment maneuver that was used early in the course of ARDS, as compared with a maneuver that consisted of cyclic change of between 5 and $45 \mathrm{~cm} \mathrm{H}_{2} \mathrm{O}$ and that was used later in the course of disease [3].

\section{Conclusions}

Obviously, the observational study by de Matos and colleagues [1] does not imply that a change in clinical practice is necessary. Currently, the routine use of recruitment maneuvers in ARDS is not recommended, but higher PEEP levels are indicated in cases that are more severe. However, this study [1] challenges the paradigm that inspiratory plateau pressures should not exceed $30 \mathrm{~cm} \mathrm{H} \mathrm{H}_{2} \mathrm{O}$ in patients with ARDS, especially when the dynamic stress/strain (that is, driving transpulmonary pressure) can be reduced and despite higher levels of PEEP. The question of whether lung recruitment maneuvers should always be used, banned definitively, or individualized (and to which targets) in ARDS remains unanswered. We are still confused but on a higher PEEP level.

\section{Abbreviations}

ARDS, acute respiratory distress syndrome; MRS, maximum recruitment strategy; PEEP, positive end-expiratory pressure.

\section{Competing interests}

The authors declare that they have no competing interests.

Authors' contributions

PMS and MGA both drafted this manuscript.

Published: 9 February 2012

\section{References}

1. de Matos GF, Stanzani F, Passos RH, Fontana MF, Albaladejo R, Caserta RE, Santos DC, Borges JB, Amato MB, Barbas CS: How large is the lung recruitability in early ARDS: a prospective case series of patients monitored by CT. Crit Care 2012, 16:R4

2. Lachmann B: Open up the lung and keep the lung open. Intensive Care Med 1992, 18:319-321.

3. Gattinoni L, Caironi P, Cressoni M, Chiumello D, Ranieri VM, Quintel M, Russo S, Patroniti N, Cornejo R, Bugedo G: Lung recruitment in patients with the acute respiratory distress syndrome. N Engl J Med 2006, 354:1775-1786

4. Mercat A, Richard JM, Vielle B, Jaber S, Osman D, Diehl J, Lefrant J, Prat G, Richecoeur J, Nieszkowska A, Gervais C, Baudot J, Bouadma L, Brochard L, Expiratory Pressure Express Study Group: Positive end-expiratory pressure setting in adults with acute lung injury and acute respiratory distress syndrome: a randomized controlled trial. JAMA 2008, 299:646-655.

5. Meade MO, Cook DJ, Guyatt GH, Slutsky AS, Arabi YM, Cooper DJ, Davies AR, Hand LE, Zhou Q, Thabane L, Austin P, Lapinsky S, Baxter A, Russell J, Skrobik Y, Ronco JJ, Stewart TE, Lung Open Ventilation Study Investigators: Ventilation strategy using low tidal volumes, recruitment maneuvers, and high positive end-expiratory pressure for acute lung injury and acute respiratory distress syndrome: a randomized controlled trial. JAMA 2008, 299:637-645.

6. Brower RG, Lanken PN, Maclntyre N, Matthay MA, Morris A, Ancukiewicz M, Schoenfeld D, Thompson BT, National Heart Lung and Blood Institute ARDS Clinical Trials Network: Higher versus lower positive end-expiratory pressures in patients with the acute respiratory distress syndrome. N Engl J Med 2004, 351:327-336.

7. Briel M, Meade M, Mercat A, Brower RG, Talmor D, Walter SD, Slutsky AS, Pullenayegum E, Zhou Q, Cook D, Brochard L, Richard JM, Lamontagne F, Bhatnagar N, Stewart TE, Guyatt G: Higher vs lower positive end-expiratory pressure in patients with acute lung injury and acute respiratory distress syndrome: systematic review and meta-analysis. JAMA 2010, 303:865-873.

8. Silva PL, Cruz FF, Fujisaki LC, Oliveira GP, Samary CS, Ornellas DS, MaronGutierrez T, Rocha NN, Goldenberg R, Garcia CSNB, Morales MM, Capelozzi VL, Gama de Abreu M, Pelosi P, Rocco PRM: Hypervolemia induces and potentiates lung damage after recruitment maneuver in a model of sepsis-induced acute lung injury. Crit Care 2010, 14:R114.

9. Borges JB, Okamoto VN, Matos GFJ, Caramez MPR, Arantes PR, Barros F, Souza CE, Victorino JA, Kacmarek RM, Barbas CSV, Carvalho CRR, Amato MBP: Reversibility of lung collapse and hypoxemia in early acute respiratory distress syndrome. Am J Respir Crit Care Med 2006, 174:268-278.

10. Terragni PP, Rosboch G, Tealdi A, Corno E, Menaldo E, Davini O, Gandini G, Herrmann P, Mascia L, Quintel M, Slutsky AS, Gattinoni L, Ranieri VM: Tidal hyperinflation during low tidal volume ventilation in acute respiratory distress syndrome. Am J Respir Crit Care Med 2007, 175:160-166.

11. Mead J, Takishima T, Leith D: Stress distribution in lungs: a model of pulmonary elasticity. J Appl Physiol 1970, 28:596-608.

doi:10.1186/cc11177

Cite this article as: Spieth PM, Gama de Abreu M: Lung recruitment in ARDS: We are still confused, but on a higher PEEP level. Critical Care 2012, 16:108. 